\title{
Magnetokinetic Probing of Extremely Fast Electron Spin Relaxation in Paramagnetic Ruthenium Complexes*
}

\author{
By Dieter Bürßner, Hans-Joachim Wolff and Ulrich E. Steiner \\ Fakultät für Chemie, Universität Konstanz, D-78434 Konstanz
}

\section{Magnetic field effects / Paramagnetic relaxation / Magnetokinetics / Photo electron transfer / Spin chemistry}

\begin{abstract}
A regularity previously observed in the ligand dependence of the magnetokinetic effect on the photoelectron transfer efficiency between photoexcited bileptic Ru-trisdiimine complexes and methylviologen has been substantiated by investigating, in addition, the bipyridine/phenanthroline series of ligands. Our theoretical model of the mechanism has been improved by taking into account non-rotational mechanisms of spin relaxation in the photooxidized $\mathrm{Ru}^{3+}$-complex. The field dependences observed for the two bileptic series of complexes can be theoretically reproduced in a very consistent way. Paramagnetic relaxation times found to range around $10^{-11} \mathrm{~s}$, reveal a striking regularity in the course of ligand variation through the bileptic series.

Eine kürzlich beobachtete Regelmäßigkeit in der Ligandenabhängigkeit des magnetokinetischen Effekts auf die Effizienz des Photoelektronentransfers zwischen photoangeregten bileptischen Ru-trisdiimin Komplexen und Methylviologen wurde an einem weiteren Beispiel, Komplexen mit der Bipyridin/Phenanthrolin Ligandenreihe, bestätigt. Unser Modell zur theoretischen Beschreibung der Magnetfeldabhängigkeit wurde verbessert, indem es nun auch rotationsunabhängige Mechanismen der Spinrelaxation im photooxidierten $\mathrm{Ru}^{3+}$-Komplex berücksichtigt. Die für die beiden bileptischen Komplexserien beobachteten Feldabhängigkeiten können theoretisch in sehr konsistenter Weise reproduziert werden. Die paramagnetischen Relaxationszeiten, die sich dabei ergeben, liegen um $10^{-11} \mathrm{~s}$ und weisen einen sehr regelmäßigen Gang mit der Ligandenvariation innerhalb der bileptischen Reihen auf.
\end{abstract}

\section{Introduction}

In liquid solution at room temperature complexes of many paramagnetic transition metal ions exhibit very short spin relaxation times $\tau_{\mathrm{s}}$, i.e. below $10^{-11} \mathrm{~s}[1]$. Since EPR spectra are observable only if

$$
\tau_{\mathrm{s}} \gg \omega_{0}^{-1}
$$

* Presented at the International Symposium "Magnetic Field and Spin Effects in Chemistry and Related Phenomena", 26-31 July 1992, Konstanz, Germany 
where $\omega_{0}$ is the Larmor frequency in the applied magnetic field, it is clear that such systems cannot be investigated by normal EPR techniques from $\mathrm{X}$-band $\left(\omega_{0}^{-1} \approx 15 \mathrm{ps}\right)$ to Q-band $\left(\omega_{0}^{-1} \approx 4 \mathrm{ps}\right)$. In fact, information on $\tau_{\mathrm{s}}$ for such systems has been obtained indirectly, usually through NMR investigation of paramagnetic compounds (cf. the monographs of Banci et al. [1] and LaMar et al. [2]). The relaxation times of nuclear spins $\left(T_{1, N}, T_{2, N}\right)$ are controlled by the stochastic motion of electron spins, whereby the fastness of electron spin relaxation is a precondition of keeping the NMR lines within an observable width. Based on quantitative theoretical relations $[2,3]$ between $\tau_{\mathrm{s}}$ and $T_{1, N}$ or $T_{2, N}, \tau_{\mathrm{s}}$ values can be deduced from the latter quantities, if some additional magnetic parameters are known. To characterize this source of information on electron spin relaxation it must be pointed out that the NMR experiments yield average information [4] on the electron spin viewed in a time window of $T_{2, N}$, usually not much shorter than $1 \mathrm{~ms}$.

In this paper we demonstrate that magnetokinetic (or spin chemical) methods can provide another access to fast electron spin relaxation if the species of interest can be made a constituent of a spin selective chemical process. In this case, the time window over which the electron spin motion is sampled, is determined by the time constants of the pertinent chemical processes which may be as short as $10^{-11} \mathrm{~s}$, i.e. just in the order of magnitude of the short paramagnetic relaxation times. In this sense, information on paramagnetic relaxation derived from magnetokinetic effects is much more "direct" than that obtained from NMR.

In this paper we will deal with $\mathrm{Ru}^{3+}$-complexes having Kramers doublet ground states (effective spin $S^{\prime}=1 / 2$ ). For them $\tau_{\mathbf{s}}$ values in the order of $10^{-11}$ to $10^{-12} \mathrm{~s}$ have been reported $[1,5]$. A magnetokinetically sensitive process in which such species are involved is the well known photooxidation of $\mathrm{Ru}(\mathrm{II})$-trisdiimine complexes by methylviologen $\left(\mathrm{MV}^{2+}\right.$ ) (cf. e. g. Ref. [14]), investigated for its magnetic field dependence in several previous reports from this laboratory and others $[6,7,8,9]$.

The photoexcited Ru-complex reacts from its lowest triplet metal-toligand charge transfer state $\left({ }^{3} \mathrm{MLCT}\right)$, originating through intersystem crossing (ISC) after optical excitation (cf. Scheme 1). A primed multiplicity symbol $3^{\prime}\left(T^{\prime}\right)$ is used to indicate some admixture of singlet multiplicity. On encounters with a suitable electron acceptor like $\mathrm{MV}^{2+}$ an electron may be transferred to form a $\left[\mathrm{RuL}_{3}^{3}{ }^{+} \ldots \mathrm{MV}^{+} \cdot\right]$ pair as the primary product, originating in its $T^{\prime}$ state due to the principle of spin conservation.

Back electron transfer (BET) from the $T$ state of the redox pair is partially spin-forbidden. Therefore, the efficiency of BET depends on the rate of spin relaxation in the Ru-moiety, which in this system contributes the fastest of the mechanisms effecting $T^{*} / S^{\prime}$ conversion. An external magnetic field also destroys the initial $T^{\prime}$ spin correlation of the pair. Due to different $g$-tensors of the two radicals efficient $T^{\prime} / S^{\prime}$ mixing occurs in a 


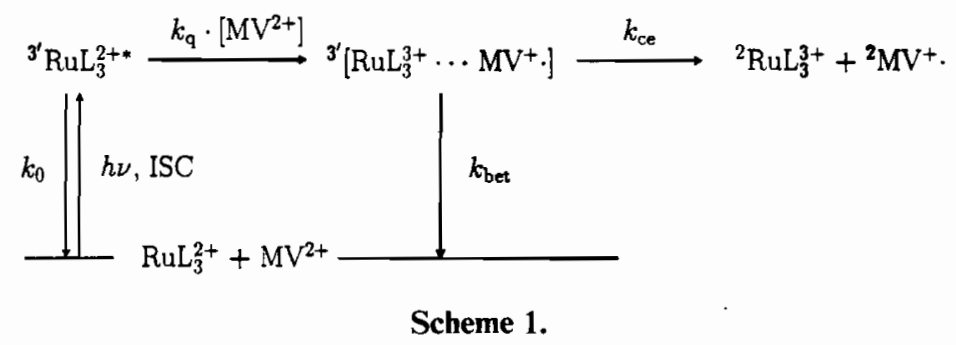

magnetic field, which results in faster BET and hence in a decreased efficiency of cage escape $\left(\eta_{\mathrm{ce}}\right)$ detectable through the yield of free radicals. The magnetic field dependence of $\eta_{\mathrm{ce}}$ provides the basis for analysis of the spin motion in the Ru(III) species.

Previously we have shown $[7,10]$ that the magnetic field effects in the system described above strongly depend on the type of ligand $L$, whereby our studies comprised substituted bipyridines, phenanthrolines and some thia- and selenaheterocyclic diimine ligands. There was no obvious correlation between ligand properties and the resultant magnetic field effects. However, employing heteroleptic complexes with mixed ligand spheres $\left(L_{n} L_{3-n}^{\prime}\right)$ for $L=2,2^{\prime}$-bipyridine (bpy) and $L^{\prime}=4,4^{\prime}$-bis(ethoxycarbonyl)2.2 'bipyridine (dce), it appeared that the ligands contributed to the magnetic field effect in a rather additive fashion. In this paper we provide some experimental evidence to corroborate this assumption by another heteroleptic series with $L=$ bpy, $L^{\prime}=$ phen $(1,10$-phenanthroline). This series was chosen because of the great similarity of the parameter values characterizing the energetics and kinetics of the photoelectron transfer reaction of these complexes with $\mathrm{MV}^{2+}$ (cf. Table 2). Thus it would be easier to exciude accidental correlations of changes in the magnetic field effect through this series with other varying parameters. Furthermore, we have modified our previous theoretical treatment of the magnetic field effect, by allowing for paramagnetic spin relaxation in the $\mathrm{Ru}^{3+}$-complex through mechanisms independent of, and much faster than, rotational diffusion, the only source of relaxation in our previous treatment [8]. The results obtained provide evidence that the ligand dependence of the magnetic field effect reflects mainly the ligand dependence of $\mathrm{Ru}^{3+}$-spin relaxation.

\section{Experimental}

The general experimental procedure comprising luminescence spectroscopy, ns-laserflash spectroscopy, and photostationary kinetic measurements, as well as the syntheses of complexes, are given in Ref. [7]. Investi- 
gated complexes not yet contained in our previous work are $\mathrm{Ru}(\mathrm{bpy})_{2}(\mathrm{phen})\left(\mathrm{PF}_{6}\right)_{2}, \mathrm{Ru}(\mathrm{bpy})(\mathrm{phen})_{2}\left(\mathrm{PF}_{6}\right)_{2}$ and $\mathrm{Ru}(\mathrm{phen})_{3}\left(\mathrm{PF}_{6}\right)_{2}$. For their syntheses the phen ligand was purchased from Merck (p.a. quality). The $\mathrm{Ru}(\mathrm{phen})_{3}\left(\mathrm{PF}_{6}\right)_{2}$-complex was synthesized following the procedures by Furrer [11], the mixed ligand (bileptic) complexes $\mathrm{Ru}(\mathrm{bpy})_{2}(\mathrm{phen})\left(\mathrm{PF}_{6}\right)_{2}$ and $\mathrm{Ru}(\mathrm{bpy})(\mathrm{phen})_{2}\left(\mathrm{PF}_{6}\right)_{2}$ were prepared according to Ref. [12] via $\mathrm{Ru}(\mathrm{bpy})_{2} \mathrm{Cl}_{2}$ and $\mathrm{Ru}$ (phen) ${ }_{2} \mathrm{Cl}_{2}$, respectively. For further details on syntheses and measurements cf. Ref. [13].

\section{Theory}

The basic theoretical concept and technical details of the model calculations have been described in Ref. [8]. Here we will only give a short outline and point out the modification which led to a considerable improvement in the modeling of the experimental results, in particular with regard to the physical consistency of the model parameters.

The spin motion and kinetic processes are described in terms of the density matrix $\varrho$ of the primary product pair $\left[\operatorname{Ru}\left(L_{n} L_{3-n}^{\prime}\right)^{3+} \cdots \mathrm{MV}^{+} \cdot\right]$ represented in the basis of the four degenerate spin-orbit states $T_{ \pm}^{v}, T_{0}^{v}$, $S^{\prime}$. The time dependence of $\varrho$ is given by the stochastic Liouville equation (SLE):

$$
\frac{d \varrho}{d t}=-\frac{i}{\hbar}[\mathbf{H}, \varrho]_{-}+\mathscr{R} \varrho-\frac{1}{2}[\mathbf{K}, \varrho]_{+}
$$

with $\mathbf{H}$, the spin Hamiltonian, $\mathscr{R}$, the relaxation super operator and $\mathbf{K}$, the reaction operator. In $\mathbf{H}$, only the effect of Zeeman interaction within the $\mathrm{Ru}^{3+}$-moiety is taken into account, which is most efficient in pair spin state mixing due to the strong anisotropy of the $g$-tensor of the $\mathrm{Ru}^{3+}$-complex. The matrix of the relaxation super operator $\mathscr{R}$ was previously derived for the mechanism of molecular rotation of the $\mathrm{Ru}^{3+}$-complex. Here, in addition, we take into account the effective contribution of any other nonrotational spin relaxation mechanism in the individual constituents of the pair characterized by spin relaxation times $T_{1, A}, T_{2, A}$ for the $\mathrm{Ru}^{3+}$-complex and $T_{1, B}, T_{2, B}$ for the counter radical. Using the definitions

$$
\begin{aligned}
& k_{1}=\frac{1}{2 T_{1, A}}+\frac{1}{2 T_{1, B}}, k_{1}^{\prime}=\frac{1}{2 T_{1, A}}-\frac{1}{2 T_{1, B}}, \\
& k_{2}=\frac{1}{T_{2, A}}+\frac{1}{T_{2, B}}, k_{2}^{\prime}=\frac{1}{T_{2, A}}-\frac{1}{T_{2, B}},
\end{aligned}
$$

the non-zero contributions to the matrix elements of $\mathscr{R}$ are given in Table 1 .

The reaction operator $\mathbf{K}$ is specified in terms of the two rate constants $k_{\mathrm{ce}}$ and $k_{\text {bet }}$, where the cage escape is not spin selective, whereas the rate of 
Table 1. Non-zero matrix elements ${ }^{\text {a }}$ of relaxation superoperator $\mathscr{R}$ with reference to basis $\mathrm{T}_{+}^{\prime}, \mathrm{T}_{-}^{\prime}, \mathrm{T}_{0}^{\prime}, \mathrm{S}^{\prime}$.

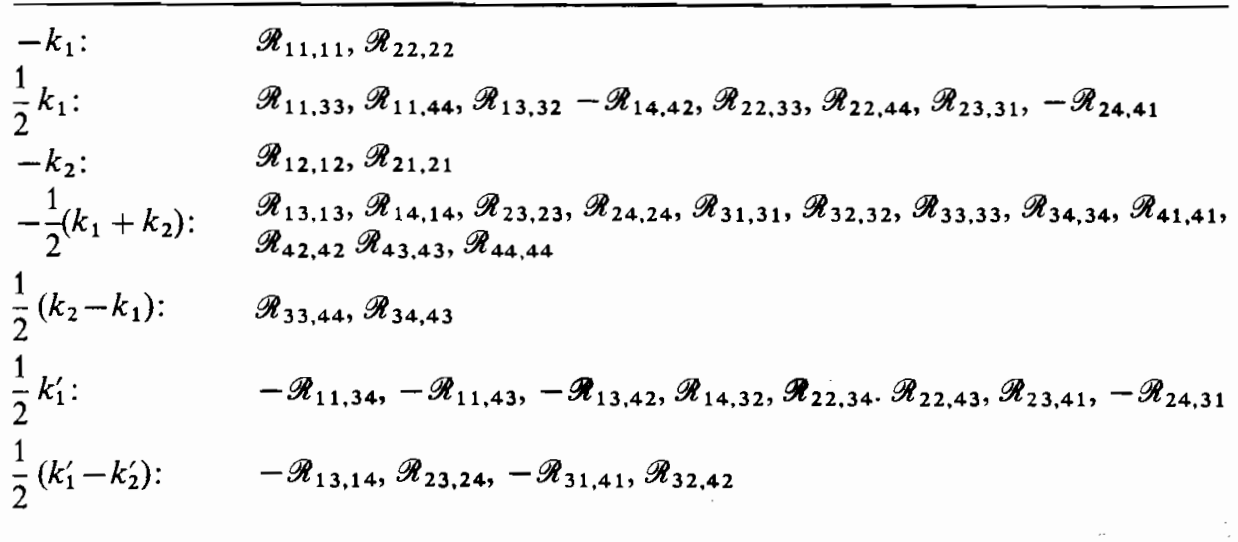

a The terms given on the left are additive contributions to the matrix elements specified on the right. A minus sign of the matrix element symbol indicates that the contribution has to be multiplied by $(-1)$.

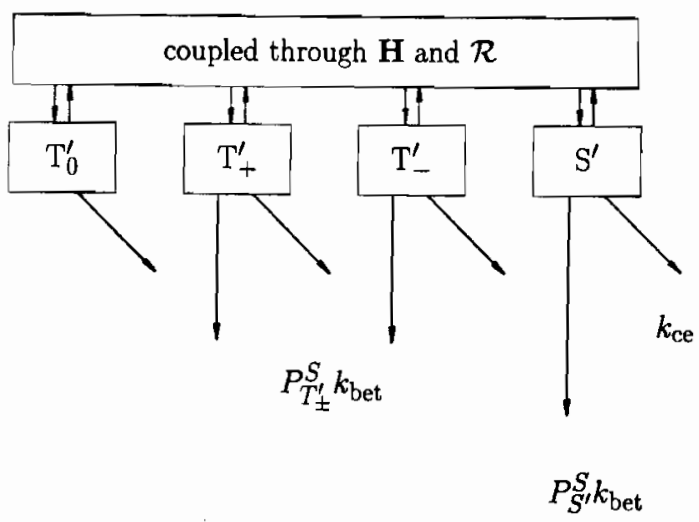

Fig. 1. Theoretical representation of the magnetokinetic behaviour of the $\left[\mathrm{RuL}_{3}^{3}+\ldots\right.$ $\mathrm{MV}^{+}$] pair. The four effective spin states $T_{ \pm}^{\prime}, T_{0}^{\prime}$ and $S^{\prime}$ are coherently coupled through $\mathbf{H}$ and incoherently through $\mathscr{R}$. The rate constant of cage escape $k_{\text {ce }}$ is the same for all spin substates. The individual rate constants of BET are proportional to the true singlet character of the respective substrates. For $T_{0}^{\prime}$ it is zero.

BET is assumed to be proportional to the true singlet character of any of the effective pair spin states $T_{ \pm}^{\prime}, T_{0}^{\prime}$ and $S^{\prime}$. A graphic visualization of the effects of the various terms in the SLE, Eq. (1) is given in Figure 1.

The time integrated solution of Eq. (1) is determined numerically as a function of orientations of the $\mathrm{Ru}^{3+}$-complex, and the solution is averaged over all orientations yielding the magnetic field dependent efficiency of 
Table 2. Characteristic photokinetic data of $\mathrm{Ru}(\mathrm{bpy})_{n}(\mathrm{phen}){ }_{3}^{2+}{ }_{n}$ complexes and parameter values $\tau_{\mathrm{s}}$ and $k_{\text {bet }}$ yielding the best fit of the magnetic field effect.

\begin{tabular}{|c|c|c|c|c|}
\hline Complex & $\mathrm{Ru}(\mathrm{bpy})_{3}^{2+}$ & $\mathrm{Ru}(\mathrm{bpy})_{2}(\mathrm{phen})^{2+}$ & $\mathrm{Ru}(\text { bpy)(phen })_{2}^{2+}$ & $\operatorname{Ru}(\text { phen })_{3}^{2+}$ \\
\hline$\lambda_{\mathrm{em}}, \mathrm{nm}$ & 610 & 610 & 610 & 605 \\
\hline$k_{0}, 10^{6} \mathrm{~s}^{-1}$ & 1.21 & 1.23 & 1.22 & 1.74 \\
\hline$k_{\mathrm{q}}, 10^{7} \mathrm{M}^{-1} \mathrm{~s}^{-1}$ & 73.6 & 69.9 & 67.5 & 98.9 \\
\hline$\Delta G_{\mathrm{el}}^{0}, \mathrm{eV}^{\mathrm{a}}$ & $-0.33^{b}$ & $-0.33^{c}$ & $-0.34^{c}$ & $-0.34^{c}$ \\
\hline$\Delta G_{\text {bet: }}^{0} \mathrm{eV}^{\mathrm{a}}$ & $-1.70^{b}$ & $-1.70^{\mathrm{c}}$ & $-1.71^{\mathrm{c}}$ & $-1.71^{\mathrm{c}}$ \\
\hline$\eta_{\mathrm{ce}}$ & 0.19 & 0.19 & 0.18 & 0.19 \\
\hline$\tau_{\mathrm{s}}, \mathrm{ps}$ & 21 & 17 & 13 & 9 \\
\hline$k_{\text {bet }}, 10^{11} \mathrm{~s}^{-1}$ & 2.41 & 2.12 & 1.73 & 1.40 \\
\hline
\end{tabular}

a The $\Delta G_{\mathrm{el}}^{0}$ and $\Delta G_{\mathrm{bet}}^{0}$ values are calculated from the redox potentials (in acetonitrile) of the ground state reactants using $\varepsilon^{0}\left(\mathrm{MV}^{+} \cdot / \mathrm{MV}^{2+}\right)-\varepsilon_{\text {sce }}^{0}=-0.46 \mathrm{~V}[14]$ and $\left(\varepsilon^{0}-\right.$ $\left.\varepsilon_{\text {sce }}^{0}\right)$ values of the complexes from the given refs. The energy of the ${ }^{3}$ MLCT state was calculated from the luminescence maximum of the respective Ru-complex (in water/ acetonitrile $1 / 1(\mathrm{v} / \mathrm{v})$ at room temperature $)$.

b Ref. [15].

- Ref. [22]. The $\varepsilon^{0}$ values of the complexes are corrected by $0.05 \mathrm{~V}$ for the sake of consistency with the value for the Ru(bpy) ${ }_{3}^{2+}$ complex given in Ref. [15].

cage escape $\eta_{\mathrm{ce}}$ as

$$
\eta_{\mathrm{ce}}=k_{\mathrm{ce}} \int_{0}^{\infty} \operatorname{Tr}[\bar{\varrho}(t)] d t .
$$

\section{Results and discussion}

The spectral and kinetic data observed by luminescence spectroscopy, nslaser flash spectroscopy and photostationary kinetic measurements for the luminescent state in the series of complexes $\left[\mathrm{Ru}(\mathrm{bpy})_{n}(\mathrm{phen})_{3-n}\right]^{2+}$ and the parameters $\left(\Delta G_{\mathrm{et}}^{0}, k_{\mathrm{q}}\right)$ characterizing the photoxidation reaction with $\mathrm{MV}^{2+}$ are given in Table 2. For comparison and because here, too. the magnetic field dependence of the cage escape efficiency have been consistently reproduced for the first time by our theoretical model, we also list. in Table 3, the corresponding results [7] for the $\left[\mathrm{Ru}(\mathrm{bpy})_{n}(\mathrm{dce})_{3-n}\right]^{2+}$ series. Whereas in the bpy/dce series the thermodynamic driving force $\Delta G_{\mathrm{et}}^{0}$ for the photochemical forward electron transfer exhibits a considerable drop when the first bpy ligand is substituted by dce, with concomitant decrease of the quenching rate constant $k_{\mathrm{q}}, \Delta G_{\mathrm{et}}^{0}$ is practically constant in the bpy/phen series and, approximately, this applies also to $k_{\mathrm{q}}$. Variations in the efficiency of cage escape, most likely controlled by variations in the rate constant of $\mathrm{BET}$, also occur only in the bpy/dce series whilst they are absent in the 
Table 3. Characteristic photokinetic data of $\mathrm{Ru}(\mathrm{bpy})_{n}(\mathrm{dce})_{3-{ }_{n}}^{2+}$ complexes and parameter values $\tau_{\mathrm{s}}$ and $k_{\text {bet }}$ yielding the best fit of the magnetic field effect.

\begin{tabular}{lllll}
\hline Complex & $\mathrm{Ru}(\mathrm{bpy})_{3}^{2+}$ & $\mathrm{Ru}(\mathrm{bpy})_{2}(\mathrm{dce})^{2+}$ & $\mathrm{Ru}(\mathrm{bpy})(\mathrm{dce})_{2}^{2+}$ & $\mathrm{Ru}(\mathrm{dce})_{3}^{2+}$ \\
\hline$\lambda_{\mathrm{em}}, \mathrm{nm}$ & 610 & 660 & 680 & 640 \\
$k_{0}, 10^{6} \mathrm{~s}^{-1}$ & 1.21 & 1.86 & 1.05 & 0.66 \\
$k_{\mathrm{q}}, 10^{7} \mathrm{M}^{-1} \mathrm{~s}^{-1}$ & 73.6 & 3.6 & 1.4 & 0.5 \\
$\Delta G_{\mathrm{et}}^{0}, \mathrm{eV}^{\mathrm{a}}$ & $-0.33^{\mathrm{b}}$ & $-0.04^{\mathrm{c}}$ & $\mathrm{d}$ & $+0.06^{\mathrm{b}}$ \\
$\Delta G_{\text {bet }}^{0}, \mathrm{eV}^{\mathrm{a}}$ & $-1.70^{\mathrm{b}}$ & $-1.84^{\mathrm{c}}$ & $\mathrm{d}$ & $-2.00^{\mathrm{b}}$ \\
$\eta_{\mathrm{ce}}$ & 0.19 & 0.12 & 0.18 & 0.31 \\
$\tau_{\mathrm{s}}, \mathrm{ps}$ & 21 & 16 & 12 & 8 \\
$k_{\text {bet }}, 10^{11} \mathrm{~s}^{-1}$ & 2.41 & 3.58 & 1.65 & 0.64 \\
\hline
\end{tabular}

a. b cf. corresponding footnotes at Table 2.

c Ref. [16].

d not available.

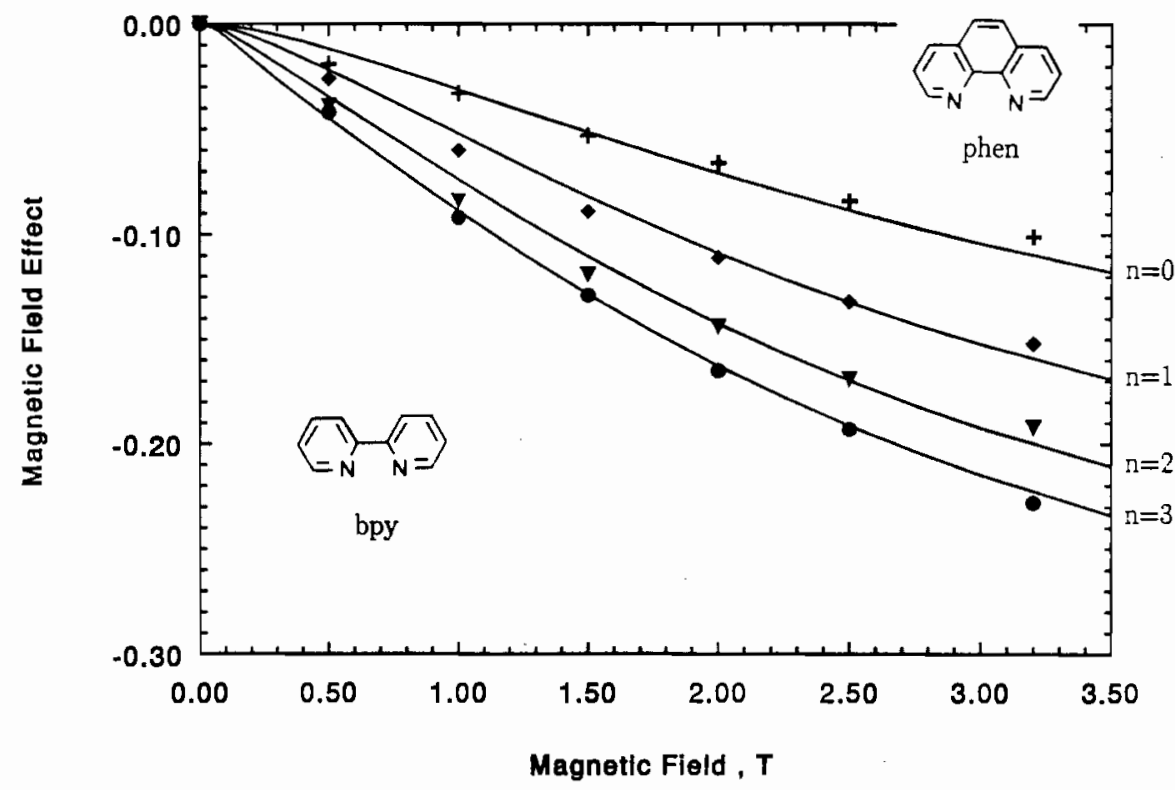

Fig. 2. Relative magnetic field effect on the cage escape efficiency $\eta_{\mathrm{ce}}$ measured with the series $\mathrm{Ru}(\mathrm{bpy})_{n}(\mathrm{phen})_{3-n}^{2+}(\bullet n=3, \nabla n=2, \bullet n=1,+n=0)$. The solid lines are results of theoretical calculations using parameter values specified in the text and in Table 2.

bpy/phen series. Thus, in a comparison of the two series it will be interesting to see if the differences noted in the kinetics will be also borne out in some way in the magnetic field effect on it.

The relative field effects on $\eta_{\mathrm{ce}}$ for the two series of complexes are shown in Figures 2 and 3. We note that, as already reported for bpy/dce, in the 


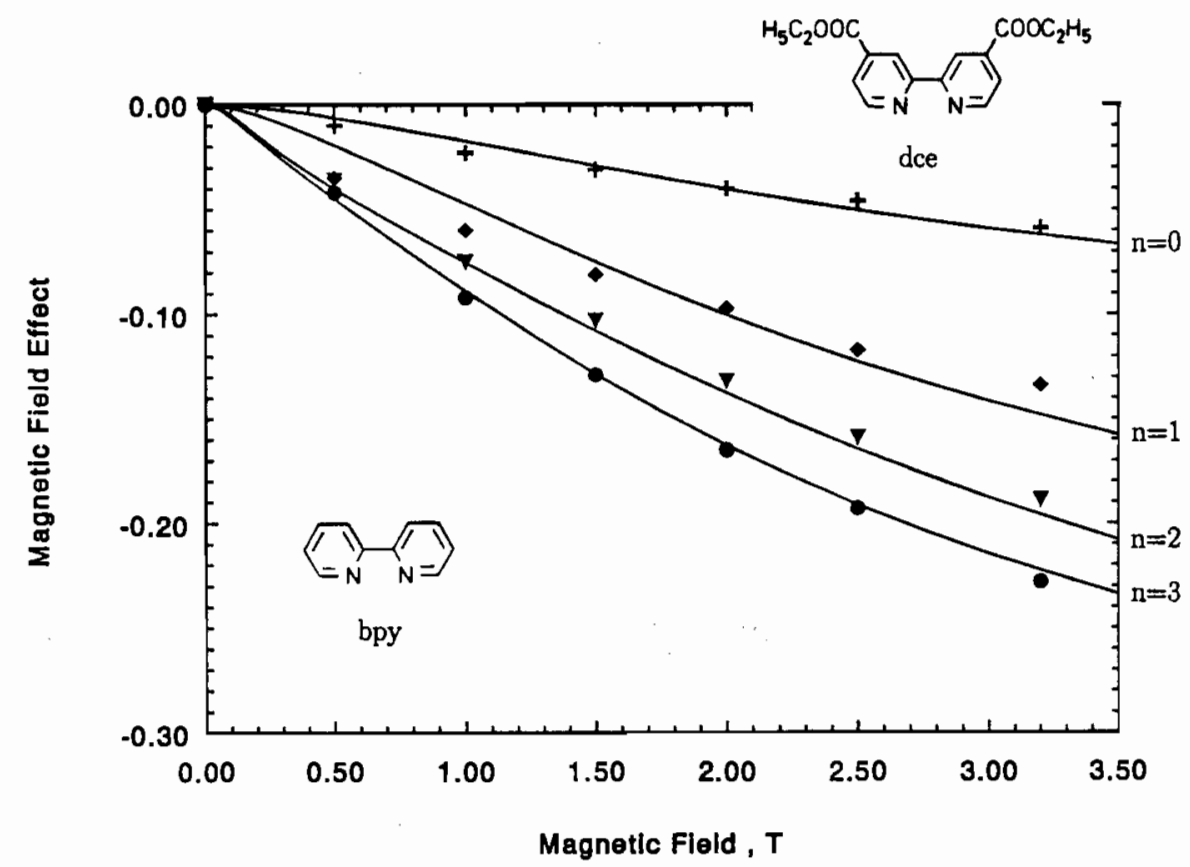

Fig. 3. Relative magnetic field effect on the cage escape efficiency $\eta_{\text {ce }}$ measured with the series $\mathrm{Ru}(\mathrm{bpy})_{n}$ (phen $)_{3-n}^{2+}(\bullet n=3, \boldsymbol{\nabla} n=2, \bullet n=1,+n=0)$ [7]. The solid lines are results of theoretical calculations using parameter values specified in the text and in Table 3.

series bpy/phen, too, the field effect decreases fairly regularly for each substitution of a bpy ligand. The field dependence curves for the different complexes in each series appear as members of a family of curves differing essentially only in their amplitude factor. The solid curves shown in the figures represent the results of our theoretical model calculations. As can be seen, the general agreement achieved with the set of measured field dependences of all the complexes is very good. The following information and principles have been employed to fix the model parameter values:

As previously, [8] $k_{\mathrm{ce}}$ was fixed to $5 \mathrm{~ns}^{-1}$, corresponding to the estimation based on the Eigen-Debye equation.

The $g$-tensor values were determined experimentally for all complexes in low-temperature solid sulfuric acid/acetonitrile matrices. It turned out that these values are essentially invariant through the series of compounds. Therefore the same values were used for all complexes. They correspond to a mixing angle of $x=67.5^{\circ}$ characterizing (through the coefficients $\sin x$ and $\cos x$ ) the spin orbit coupling (SOC) induced mixing of $a_{1}$ - and $e$-symmetry type $d$-orbital components in the lowest $\mathrm{Ru}^{3+}$ Kramers doublet state.

Our description of spin relaxation through non-rotational mechanisms in the $\mathrm{Ru}^{3+}$-complex is characterized by the assumption $T_{1}=T_{2} \equiv \tau_{\mathrm{s}}$, 


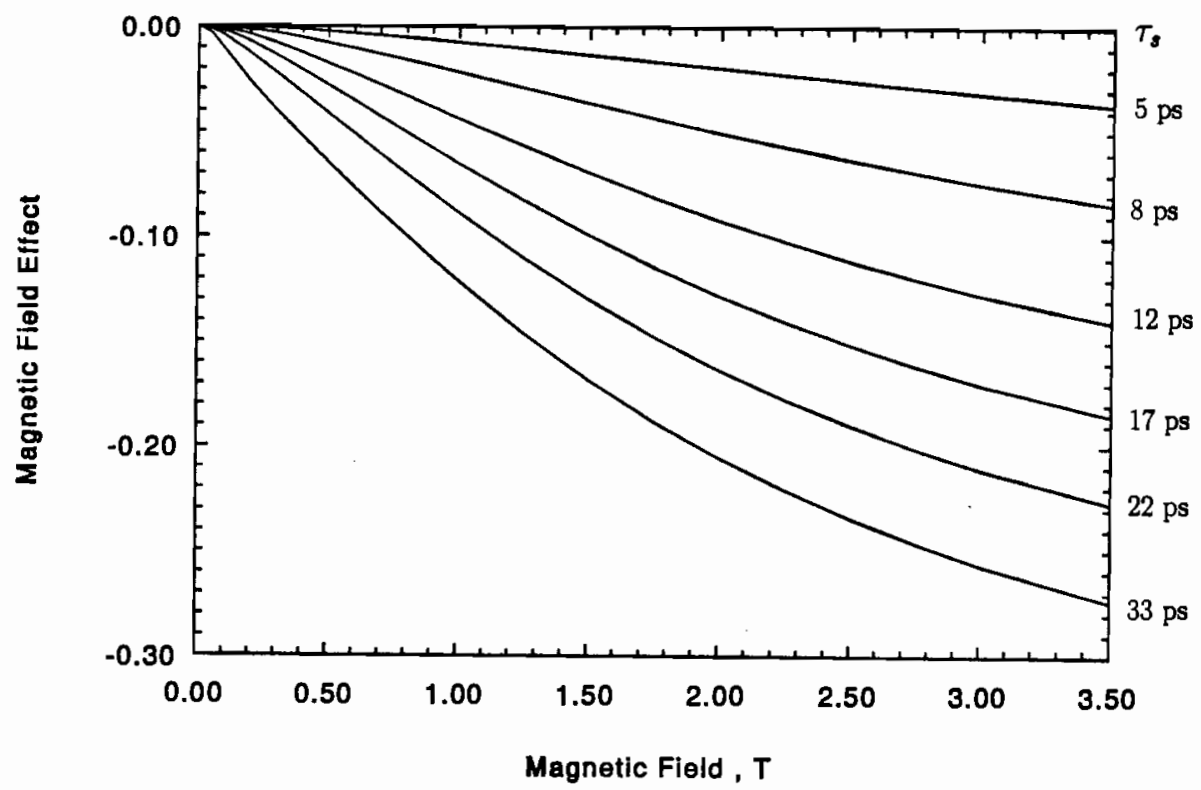

Fig. 4. Relative magnetic field effect on the cage efficiency $\eta_{\mathrm{ce}}$ according to model calculations with parameter values $s=0.0, k_{\mathrm{ce}}=5.0 \mathrm{~ns}^{-1}, D_{\mathrm{r}}=1.0 \mathrm{~ns}^{-1}, x=67.5^{\circ}$, $\eta_{\mathrm{ce}}(\mathrm{B}=0)=0.25 \mathrm{kept}$ fixed and $\tau_{\mathrm{s}}$ varied as indicated.

where $\tau_{s}$ is a magnetic field independent fit parameter. The assumptions made, imply that the correlation time $\tau_{\mathrm{c}}$ of the stochastic perturbation inducing the relaxation is much shorter than $\omega_{0}^{-1}$ which certainly is the case if $\tau_{\mathrm{s}}$ is found to be in the order of $10^{-11} \mathrm{~s}$ or shorter. The rotational contribution of $\mathrm{Ru}^{3+}$ spin relaxation is taken into account as previously described using $D_{\mathrm{r}}=1 \mathrm{~ns}^{-1}$ and a $\gamma$-tensor in accord with the above given mixing angle of $x=67.5^{\circ}$. However, it must be emphasized that in the present treatment the rotational mechanism contributes only to a minor extent as compared to the non-rotational mechanisms. The effect of spin relaxation in the $\mathrm{MV}^{+} \cdot$ radical (with $T_{2}$ in the range of $10^{-6}$ to $10^{-7} \mathrm{~s}$ ) on the spin motion of the $\left[\mathrm{Ru}^{3+} \cdot \mathrm{MV}^{+} \cdot\right]$ pair has been considered negligible.

Finally, the value of $k_{\text {bet }}$ was fixed subject to the condition that the model calculation has to yield the correct experimental vlaue of $\eta_{\mathrm{ce}}$ at zero field.

In our previous treatment satisfactory modeling of the observed curvature of the magnetic field effect, particularly at low fields, was not possible without assuming a considerable fraction of the primary redox pair originating with effective singlet spin (i.e. $s=0.45$ ), which conflicts with the generally assumed essential triplet nature of the photoreactive state or the principle of spin conservation during electron transfer processes, and the magnetic field effect amplitude was not correctly reproduced without assuming an unphysically high value of the rotational diffusion constant $D_{\mathrm{r}}$. 
With the present modification, these problems have disappeared. As is shown in Figure 4, with $s=0$, i.e. producing the primary redox pair in a formal triplet state, variation of $\tau_{\mathrm{s}}$ as the only free parameter yields a family of curves which nicely reflects the type of change observed with our ligand variation. The actual value of $\tau_{\mathrm{s}}$ used in the fits shown in Figures 2 and 3 and the $k_{\text {bet }}$ values following from the above mentioned condition are given in Tables 2 and 3.

The $\tau_{\mathrm{s}}$ values obtained range between 8 and 21 ps and are in general agreement with NMR data for comparable $\mathrm{Ru}^{3+}$-complexes. For example a constant value of 20 ps was evaluated by Doddrell et al. [5] for Ru(acac) 3 in a field range from 0.2 to $6 \mathrm{~T}$. More specifically, our linewidth analysis of the ${ }^{1} \mathrm{H}-\mathrm{NMR}$ spectra of $\mathrm{Ru}(\mathrm{bpy})_{3}^{3+}$ and $\mathrm{Ru}(\mathrm{phen})_{3}^{3+}$ published by DeSimone and Drago [17] revealed that electron spin relaxation in the latter is about twice as fast as in the former, in fair accord with our magnetokinetic finding.

What is most intriguing in our results on $\tau_{\mathrm{s}}$ is the very regular fashion in which these values depend on the ligand sphere: with each replacement of a bpy ligand by either a phen or a dce ligand the spin relaxation time is reduced by about 4 ps. This observation strongly indicates that spin relaxation in complexes of the investigated type is brought about by independent contributions of the individual ligands. To our knowledge, no paramagnetic NMR spectra of heteroleptic series of complexes have been investigated so far. Therefore, to corroborate our interesting magnetokinetic result, such NMR investigations are in progress in our laboratory.

What mechanisms can be put forth to account for the evaluated short spin relaxation times and their ligand dependence? If $\tau_{\mathrm{s}} \ll \tau_{\text {rot }}$, the orientational correlation time of the paramagnetic species, the mechanism must be clearly non-rotational. Of these mechanisms Kivelson [18] favoured the Orbach mechanism as the leading one. Here electric field fluctuations arising through molecular motions of the solvent induce thermally activated spin-flip transitions associated with electronic excitation to the lowest excited electronic state. Kivelson's treatment allows only for a rough estimation of the $T_{1}$-time. However, it seems difficult to account for a relaxation time as short as $10^{-11} \mathrm{~s}$ with his formula for the Orbach process. Furthermore his expression is simplified to an extent as to disregard any specific ligand effect.

Noting the shortcomings of the electronic Orbach mechanism Kleinschmidt et al. [19] suggested that in $S=1 / 2$ transition metal complexes with ground states of basic $T$ or $E$ orbital degeneracy, however split by $\Delta \lesssim 1000 \mathrm{~cm}^{-1}$ due to SOC and molecular distortions, electric field fluctuations from solvent motion can induce spin-flips associated with excitation of low-frequency vibrational modes of the electronic ground state. Thereby $10^{-11} \mathrm{~s}$ appears as a reasonable estimate of $\tau_{\mathrm{s}}$. Furthermore this mechanism can provide a straight-forward explanation of specific ligand effects due to 
the dependence of $\tau_{\mathrm{s}}^{-1}$ on the square of the frequency of some soft (i.e. low frequency) vibration of a ligand within the ligand sphere. Our data will provide a basis for a critical test of this hypothetic mechanism.

The $k_{\text {bet }}$ parameters fixed by the choice of the $\tau_{\mathrm{s}}$-value are also given in Tables 2 and 3 . They are in the order of $10^{11} \mathrm{~s}^{-1}$ and by about a factor of 10 larger than the $k_{\text {bet }}$ values evaluated previously [7] for the average rate constant of BET. Note that the latter values correspond to effective rate constants, i.e. a reaction model that does not differentiate between the steps of spin conversion and of (spin conserving) BET, while $k_{\text {bet }}$ pertains to the reactivity of a hypothetically pure singlet pair.

The $k_{\text {bet }}$ values derived for the bpy/dce series pass through a maximum at $\Delta G_{\mathrm{et}}^{0} \approx-1.85 \mathrm{eV}$, an observation that is in accord with some of the recently observed "bell shaped" $\lg k_{\text {bet }}\left(\Delta G_{\text {bet }}^{0}\right)$ dependence with a maximum close to $-1.9 \mathrm{eV}[20,21]$. Such a behaviour, basically known as the transition of the Marcus normal to inverted region, can be sensibly modeled by results of current electron transfer theory (cf. Gould et al. [20] for references).

In the bpy/phen series $k_{\text {bet }}$ shows a weak decrease as $\tau_{\mathrm{s}}$ drops from (bpy) to (phen) $)_{3}$. Although, in view of the constancy of $\Delta G_{\text {bet }}^{0}$ no significant change of $k_{\text {bet }}$ is expected, one should be aware that in general the standard deviation of $\lg k_{\mathrm{et}}\left(\Delta G_{\mathrm{et}}^{0}\right)$ correlations is larger than the equivalent of a factor of 2 in $k_{\mathrm{et}}$, which is more than observed here. We will not speculate about possible origins of such small variations.

\section{Conclusions}

In this contribution we have extended the experimental basis substantiating a regular variation of the magnetokinetic effect with bileptic series of $\mathrm{Ru}^{3+}$ trisdiimine-complexes.

Incorporating the contribution of non-rotational spin relaxation of the paramagnetic complexes into our magnetokinetic theory has led to a fundamental improvement in the modeling of the observed magnetic effects within the limits of physically sensible parameter values. In particular, the observed effects are found to be in accord with the assumption that the primary pair of redox products originates with essential triplet spin, and the ligand dependence of the magnetic field effect can be traced back to the ligand dependence of paramagnetic relaxation to which the ligands contribute in a nearly additive fashion. An important relation between our magnetokinetic type of measurement and paramagnetic NMR has been pointed out and a stimulating interaction between these very different techniques of experimental access to short paramagnetic relaxation times may be anticipated. 


\section{Acknowledgement}

Financial support of this research by the Deutsche Forschungsgemeinschaft and the Fonds der Chemischen Industrie is gratefully acknowledged. We like to thank Dr. Y. Serebrennikov for stimulating discussions about the mechanisms of paramagnetic relaxation.

\section{References}

1. L. Banci, I. Bertini and C. Luchinat, Nuclear and Electron Relaxation, Verlag Chemie, Weinheim, 1991.

2. G. N. LaMar, W. DeW. Horrocks, Jr., R. H. Holm, Eds., NMR of Paramagnetic Molecules, Academic Press, New York 1973.

3. K. V. Vasavada and B. D. Nageswara Rao, J. Magn. Reson. 81 (1989) 275.

4. D. T. Pegg and D. M. Doddrell, Chem. Phys. Lett. 81 (1976) 607.

5. D. M. Doddrell, D. T. Pegg, M. R. Bendall and A. K. Gregson, Aust. J. Chem. 30 (1977) 1635.

6. U. E. Steiner, H.-J. Wolff, T. Ulrich and T. Ohno, J. Phys. Chem. 93 (1989) 5147.

7. H.-J. Wolff and U. E. Steiner, Z. Phys. Chem. Neue Folge 169 (1990) 147.

8. U. E. Steiner and D. Bürßner, Z. Phys. Chem. Neue Folge 169 (1990) 159.

9. G. Feraudi and G. A. Argüello, J. Phys. Chem. 92 (1988) 1846.

10. H.-J. Wolff, D. Bürßner, G. Orellana, H. Rau and U. E. Steiner, paper presented at the 46. Bunsenkolloquium, Erlangen 1990.

11. G. Furrer, Diploma Thesis, Universität Fribourg, 1987.

12. G. Sprintschnik, H. W. Sprintschnik, P. P. Kirsch and D. G. Whitten, J. Am. Chem. Soc. 99 (1977) 4947.

13. H.-J. Wolff, Doctoral Thesis, Universität Konstanz, 1993.

14. K. Kalyanasundaram, Coord. Chem. Rev. 46 (1982) 159.

15. C. M. Elliott, R. A. Freitag and D. H. Bleany, J. Am. Chem. Soc. 107 (1985) 4647.

16. C. M. Elliott and E. J. Hershenhart, J. Am. Chem. Soc. 104 (1982) 7519.

17. R. E. DeSimone and R. S. Drago, J. Am. Chem. Soc. 92 (1970) 2343.

18. D. Kivelson, J. Chem. Phys. 45 (1966) 1324.

19. K. M. Kleinschmidt, J. F. Dobson, D. M. Doddrell, Chem. Phys. Lett. 68 (1979) 115.

20. I. R. Gould, J. E. Moser, D. Ege and S. Farid, J. Am. Chem. Soc. 110 (1988) 1991.

21. K. Kikuchi, Y. Takahashi, M. Hoshi, T. Niwa, T. Katagiri and T. Miyashi, J. Phys. Chem. 95 (1991) 2378.

22. R. J. Staniewicz, R. F. Sympson and D. G. Hendricker, Inorg. Chem. 16 (1977) 2166. 